\title{
Komunikasi Ritual Suroan pada Masyarakat Suku Jawa di Kota Bengkulu
}

\author{
Siroy Kurniawan \\ Pascasarjana Komunikasi Penyiaran Islam \\ Universitas Islam Negeri Sunan Kalijaga Yogyakarta
}

Korespodensi dengan Penulis:

Siroy Kurniawan, Telp: 085266055751

E-mail: siroykurniawan@gmail.com

\section{Keywords: Communication, Symbol, Ritual, Suroan, Sausanne Langer.}

\begin{abstract}
Traditional rituals wrapped in religious nuances are quite diverse in Indonesia. One of the traditional rituals that is still preserved today is the suroan ritual. The suroan ritual is a memorial to the annual agenda in welcoming the Islamic newyear. Suroan in the Javanese calendar coincides with the calendar of the Islamic Hijri newyear falling in the month of Muharram. The suroan ritual carried out by the Javanese pzeople is still preserved. Like suroan in Bengkulu, Javanese people who have moved for decades from Java to Bengkulu, they still carry out this Suroan warning with complete symbols. The symbols used in the Suroan ritual have profound meanings. The meaning contained in these symbols becomes one of the cultural propaganda communication movements wrapped in religious nuances. The meanings contained include: 1). Takir Plontang, is interpreted as a form of solidarity, interrelation with one another among Muslims to maintain harmony, peace and blessings in life. 2). Sodo, symbolizes the bond of the two sentences of shahada which gives peace and blessings in Islam. 3). Janur Kuning, the philosopher that the yellow palm signifies the existence of light, an illumination for Muslims. The local community feels a strong Islamic ukhuwah, looking after each other, protecting and protecting one another. This research provides an explanation to the public that traditional rituals have meaning that is full of important lessons in life. So that people should continue to preserve traditional rituals as they should.
\end{abstract}

\begin{abstract}
Abstrak
Ritual tradisional yang dibalut nuansa keagamaan cukup beragam di Indonesia. Ritual tradisional yang masih dilestarikan hingga saat ini salah satunya adalah ritual suroan. Ritual suroan menjadi peringatan agenda tahunan dalam menyambut tahun baru Islam. Suroan dalam kalender Jawa bertepatan dengan penanggalan tahun baru Islam Hijriah jatuh pada bulan Muharram. Ritual suroan yang di laksanakan oleh masyarakat Jawa masih tetap terjaga kelestariannya. Seperti halnya suroan yang ada di Bengkulu, masyarakat jawa yang sudah pindah berpuluh-puluh tahun dari jawa ke Bengkulu mereka masih tetap melaksanakan perigatan Suroan ini dengan Simbol-simbol yang lengkap.
\end{abstract}


Simbol-simbol yang di gunakan dalam ritual suroan memiliki makna yang mendalam. Makna yang terdapat dalam simbol-simbol tersebut menjadi salah satu gerakan komunikasi dakwah kultural yang berbalut nuansa keagamaan. Makana-makna yang terkandung antara lain: 1). Takir Plontang, dimaknai sebagai bentuk solidaritas, keterkaitan satu sama lain antar umat Islam untuk menjaga kerukunan, kedamaian dan keberkahan dalam kehidupan. 2). Sodo, melambangkan ikatan dua kalimat syahadat yang memberikan kedamaian dan keberkahan dalam Islam. 3). Janur Kuing, filosof bahwa janur kuning menandakan adanya cahaya, sebuah penerangan bagi umat islam. Masayarakat setempat merasakan adanya sebuah ukhuwah islamiah yang kuat, saling menjaga, melndungi dan mengayomi satu sama lain. Penelitian ini memberikan penjelasan kepada masyarakat bahwa ritual tradisional memiliki makna yang sarat akan pelajaran penting dalam kehidupan. Sehingga hendaklah masyarakat untuk terus melestarikan ritual tradisional sebagai mana mestinya.

\section{PENDAHULUAN}

Penyebaran Islam di Indonesia memiliki riwayat yang sangat panjang. Islam masuk ke Indonesia melalui berbagai jalur, salah satunya melalui jalur budaya. Sehingga masyarakat Indonesia mengalami akulturasi dengan berbagai bentuk budaya yang ada. Oleh karena itu corak dan bentuknya dipengaruhi oleh berbagai unsur budaya dan agama yang bermacam-macam. Peranan kebudayaan menjadi sangat besar dalam ekosistem komunikasi, karena karakteristik kebudayaan antar komunitas dapat membedakan kebudayaan lisan dan tulisan yang merupakan kebiasaan suatu komunitas dalam mengkomunikasikan adat istiadatnya. ${ }^{1}$ Salah satu konsep yang berkaitan dengan kebudayaan adalah kebudayaan tradisional. Kebudayaan tradisional adalah prilaku yang merupakan kebiasaan atau cara berfikir dari suatu kelompok sosial yang ditampilkan melalui tidak saja adat istiadat tertentu tetapi juga prilaku adat istiadat yang diharapkan oleh anggota masyarakatnya. ${ }^{2}$

Kebudayaan tradisional tidak pernah lepas dari kehidupan. Banyak pelaksanaan kegiatan ritual budaya yang diiringi ajaran Islam. Salah satunya adalah perayaan Suroan atau dalam kalender Islam perayaan tahun baru Islam. Istilah Suro berasal dari bahasa Arab شوراء ('asyura) yang berarti kesepuluh (10 Muharram). Istilah tersebut kemudian dijadikan sebagai bulan permulaan hitungan dalam takwin Jawa. Bagi masyarakat Jawa, kegiatan-kegiatan menyambut bulan Suro sudah berlangsung sejak berabad-abad yang lalu. Suroan menitik beratkan pada ketentraman batin dan keselamatan. Karenanya, pada malam satu Suro biasanya

\footnotetext{
${ }^{1}$ Alo Liliweri, “Dasar-Dasar Komunikasi Antarbudaya”, (Yogyakarta: Pustaka Pelajar, 2009), hlm.109.

2 Ibid., hlm. 113.
} 
selalu diselingi dengan ritual pembacaan doa dari semua umat yang hadir merayakannya. Hal ini bertujuan untuk mendapatkan berkah dan menangkal datangnya marabahaya.

Banyak kegiatan syarat makna yang dilaksanakan pada malam satu Suro. Di Ponorogo, perayaan satu suro diisi dengan berbagai aktivitas seperti Festival Reog Nasional, Pawai lintas sejarah, Kirab pusaka, dan Ralungan risalah doa di telaga ngebel. Kegiatan ini merupakan agenda tahunan bagi masyarakat setempat diberi nama Grebeg Suro. Di desa Mlangi Nogotirto Sleman Yogyakarta, peringatan Asyura dilakukan dengan memasak Sega Megana yang dibawa ke masjid untuk dibagikan kepada anak-anak, terutama anak yatim, sementara orang-orang dewasa pada hari itu melakukan puasa sunnah. Tidak jauh berbeda dengan dikota Gede, tepatnya di dusun Darakan, pada tanggal 10 Muharam masyarakat (terutama generasi tua) membuat jenang panggul. Pembuatan jenang panggul dimaksudkan untuk menolak bahaya. ${ }^{3}$

Di Solo, biasanya dalam perayaan satu Suro terdapat hewan kahas yakni kebo (kerbau) bule. Keikut sertaan kebo bule ini konon dianggap keramat oleh masyarakat setempat. ${ }^{4}$ Berbeda dengan solo di Semarang perayaan malam satu suro dilakukan ritual Kungkum tradisi ini dilakukan dengan cara berendam di sugai selama malam satu suro. Tujuan dari tradisi ini adalah untuk menyucikan kotoran rohani dan jasmani. Di Jawa Barat terdapat tradisi Bubur Suro, bubur ini terbuat dari beras, santan, garam, jahe dan sereh. Bubur ini dihiasi dengan topping serpihan jeruk bali, dan butiran delima serta 7 jenis kacang seperti kacang tanah, kacang mede, kacang hijau, kedelai, kacang merah, kacang tholo dan kacang bogor. Hal ini sebagai refleksi kesungguhan tekad untuk menjalani tahun depan. ${ }^{5}$

Sulawesi dan Sumatra juga memiliki kegiatan perayaan malam satu suro yang menjadi ritual-ritual sakral dalam pelaksanaaannya. Di pulau Sulawesi perayaan satu Suro membuat bubur yang diberi nama Bubur Jepe Suro (bubur Muharam) yang dilakukan di masyarakat Takalar, Sulawesi Selatan. Perayaan bubur ini diyakini dapat mendatangkan rezeki yang melimpah. Di pulau Sumatera terdapat perayaan tahun baru Islam seperti di Aceh, untuk memperingati bulan Asyura masyarakat membuat Kanji Asyura yang terbuat dari beras, susu, kelapa, gula, buah-buahan, kacang tanah, pepaya, delima, pisang dan akar-akaran. Setiap bulan Muharam masyarakat Aceh memasak Kanji Asyura di suatu tempat, kemudian dibawa ke masjid

\footnotetext{
3 Japarudin, "Tradisi Bulan Muharam Indonesia", Tasaqofah dan Tarikh: Jurnal Kebudayaan dan Sejarah Islam, Vol. 2, No. 02, 2017, hlm. 170.

4 Setia Rahadi, "Perayaan Satu Suro Tradisi malam Sakral Masyarakat Jawa", https://www.indonesiakaya.com/jelajah-indonesia/detail/perayaan-satu-suro-tradisi-malam-sakralmasyarakat-jawa 2015. Diakses pada 25 Oktober 2019.

5 Novitasari, "Tradisi Unik Perayaan Muharam di Indonesia", https://kumparan.com/ariulandari/17-tradisi-unik-perayaan-muharam-tahun-baru-kalender-bulan-di-indonesia 2017. Diakses pada 25 Oktober 2019.
} 
atau perempatan jalan dan setealah dibacakan doa dibagikan kepada masyarakat. ${ }^{6}$ Sumatera Barat tepatnya di Pariaman dalam menyambut tahun baru Islam melaksanakan ritual yang disebut Tabuik. Di Bengkulu juga terdapat perayaan satu muharam yang disebut Tabut, Tabut merupakan ritual adat istiadat yang dilaksanakan masyarakat Kerukunan Keluarga Tabut (KKT) dalam penyambutan tahun baru Islam. Ritual Tabut dianggap sangat sakral bagi masyarakat KKT dan masyarakat Kota Bengkulu, dan beranggapan bahwa Tabut dilaksanakan agar terhidar dari segala macam kesusahan dan menolak balak (bencana) ${ }^{7}$.

Di Kota Bengkulu selain perayaan Tabut, juga memiliki kegiatan lain pada saat tanggal 10 Muharam yang dilaksanakan oleh masyarakat Suku Jawa. Masyarakat Bengkulu yang melaksanakan ritual Suroan adalah Masyarakat Jawa RT 14 Padang Serai Kota Bengkulu. Perayaan malam suroan ini dilaksanakan pada malam hari, yang dimulai dengan pengajian, doa tolak balak, dan diakhiri makan bersama. Kegiatan tersebut dilaksanakan di masjid atau mushola. Kemudian dalam pelaksanaan ritual suroan, masyarakat membuat makanan khusus yang di sebut takir pelontang. Takir plontang berisikan nasi dan lauk pauk yang dibungkus dengan wadah dari daun pisang yang dibentuk segi empat dan dikelilingi janur kuning. Takir yang dibawa ke masjid sesuai dengan jumlah anggota keluarganya dan kemudian dilebihkan satu untuk rumah mereka sebagai tempat berlindung. Hal ini dikarenakan agar anggotanya mendapatkan berkah yang berlimpah dan menjauhkan dari balak di tahun yang akan datang. Kegiatan ritual Suroan bertujuan untuk mendapatkan keselamatan dan keberkahan dalam kehidupan dunia dan akhirat. ${ }^{8}$

Studi tentang Ritual Suroan tidak banyak dikaji. Siburian dan Malau meneliti Ritual Suroan Masyarakat Jawa membahas mengenai pentingnya ritual suroan bagi suku Jawa, penelitian ini menggunakan teori religi dan kebudayaan untuk mengungkap pentingnya Ritual Suroan tersebut. ${ }^{9}$ Ini berbeda dengan apa yang peneliti maksud dalam studi ini bahwa penting melihat makna simbol yang terdapat dalam ritual suroan. Peneliti menggunakan pisau bedah Sausanne Langer dalam memahami simbol. Simbol menjadi sesuatu yang sentral dalam kehidupan manusia. Manusia memiliki kemampuan untuk menggunakan simbol dan manusia memiliki kebutuhan terhadap simbol yang sama pentingnya dengan kebutuhan terhadap makan dan tidur. Kita mengarahkan dunia fisik dan sosial kita melalui simbol dan maknanya.

Langer memandang "makna" sebagai suatu hubungan yang kompleks di antara simbol, objek dan orang. Jadi makna terdiri dari aspek logis dan aspek pisikologis. Aspek logis adalah

${ }^{6}$ Japarudin, “Tradisi Bulan Muharam Indonesia”... hlm. 171.

7 Ibid., hlm.174-176.

${ }^{8}$ Observasi Lapangan Masyarakat RT 14 Kelurahan Padang Serai Kota Bengkulu, 05 Desember 2017.

${ }^{9}$ Ayu Lusoi M. Siburian dan Waston Malau, "Tradisi Ritual Suroan pada Masyarakat Jawa di Desa Sambirejo Timur Precut Sei Tuan", Gondang: Jurnal Seni dan Budaya, Vol. 2, No. 2, Januari 2018. 
hubungan antara simbol dan referennya, yang oleh Langer dinamaakan "denotasi". Adapun aspek psikologis adalah hubunga antara simbol dan orang yang disebut "konotasi". ${ }^{10}$ Teori ini penulis gunakan untuk mengungkap bagaimana proses ritual suroan ini berlangsung dari awal hingga akhir, kemudian menemukan makna yang terkandung dalam komponen-komponen yang terdapat dalam ritual suroan tersebut. Sehingga diharapkan penelitian ini mampu memberikan gambaran budaya Indonesia yang begitu beragam dengan ciri khas dan makna keislaman yang melekat antara budaya dan agama.

\section{METODE}

Penelitian ini menggunakan pendekatan kualitatif. Wawancara dan observasi telah digunakan untuk mendapatkan data primer dan dokumentasi untuk memeperoleh data sekunder. Dalam penelitian ini teknik analisis data yang penulis gunakan yaitu menggunakan Teori Simbol yang diciptakan Sausanne Langer adalah teori terkenal dan dinilai bermanfaat karena mengemukakan sejumlah konsep dan istilah yang biasa digunakan dalam ilmu komunikasi. Simbol menjadi sesuatu yang sentral dalam kehidupan manusia. Manusia memiliki kemampuan untuk menggunakan simbol dan manusia memiliki kebutuhan terhadap simbol yang sama pentingnya dengan kebutuhan terhadap makan dan tidur. Kita mengarahkan dunia fisik dan sosial kita melalui simbol dan maknanya. Dari penjelasan di atas berangkat dari teori Sausanne Langer peneliti memfokuskan pada dua aspek yaitu aspek logis dan aspek psikologis.

Bagan 1. Kerangka Pemikiran

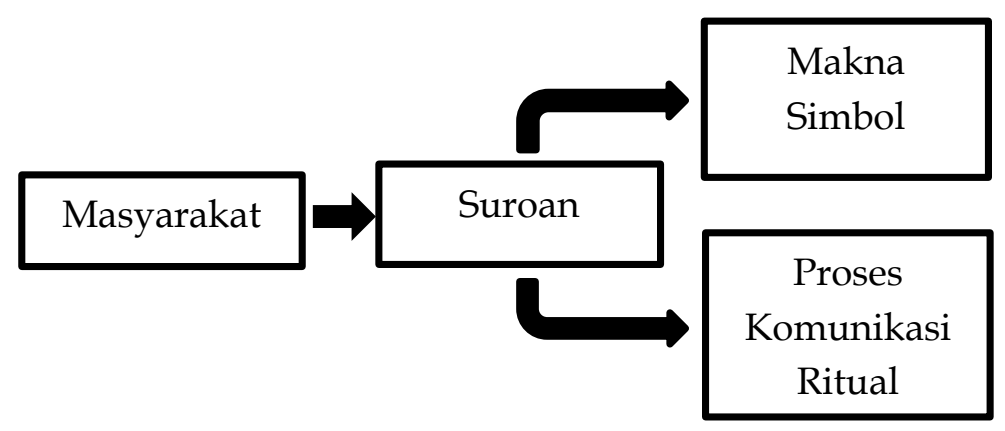

Keterangan :

1. Masyarakat sebagai subjek (pelaksana Ritual Suroan)

2. Suroan sebagai kegiatan yang menjadi objek penelitian

3. Makna simbol sebagai pesan dalam ritual Suroan.

4. Proses komunikasi ritual Suroan (proses kegiatan)

${ }^{10}$ Morissa, "Teori Komunikasi Individu hingga Massa”, (Jakarta: Kencana. M. Djupri. 2011). hlm. 135136. 
5. Persepsi masyarakat tentang ritual Suroan (feedback)

Dari bagan di atas dapat di ambil kesimpulan bahwa komunikasi ritual menitik beratkan pada sebuah makna dari simbol-simbol yang dipakai dalam ritual yang di maksud. Kemudian dari ritual tersebut melahirkan sebuah pemahaman dan pemaknaan yang di maknai oleh masyarakat sebagai nilai budaya dan terus dilestariakan.

\section{HASIL DAN PEMBAHASAN}

\section{Proses Komunikasi Ritual Suroan}

Komunikasi ritual diyakini tetap ada sepanjang zaman. Ini disebabkan kebutuhan manusia, meskipun bentuknya berubah-ubah demi pemenuhan kebutuhan dirinya sebagai mahluk individu, anggota komunitas, mahluk sosial, dan sebagai salah satu bagian dari alam semesta. ${ }^{11}$ Salah satu bentuk komunikasi ritual adalah dalam perayaan ritual Suroan yang diaksanakan oleh masyarakat RT 14 Kelurahan Padang Serai Kota Bengkulu. Ritual Suroan adalah suatu acara menyambut Tahun Baru Islam yang di laksanakan pada malam hari tepat tanggal 10 Asuro atau jika dalam kalender Islam 10 Muharam. Ritual Suroan dilaksanakan pada malam hari sesudah sholat Isya, semua masyarakat RT 14 berbondong-bondong datang ke masjid untuk mengikuti kegiatan Ritual Suroan dengan membawa nasi Takir yang sudah disediakan dan berjumlah sesuai dengan jumlah anggota keluarga dan dilebihkan satu untuk rumah sebagai perlindungan. Perayan ini bertujuan sebagai ungkapan rasa syukur kepada sang pencipta atas nikmat yang telah diberikan dan memohon ampunan agar di berikan keselamatan, dijauhkan dari balak atau bahaya dan kembali pada fitrahnya untuk melaksanakan kehidupan di tahun yang baru.

Ritual Suroan merupakan Ritual Islam yang berbentuk tertier, ritual yang berupa anjuran dan tidak sampai pada derajat Sunnah. Dalam hadis yang diriwayatkan oleh Imam Al-Nasa'i dan Ibnu Hibban yang menyatakan bahwa Nabi Muhammad SAW bersabda "orang-orang yang membaca ayat kursy setelah shalat wajib, tidak akan ada yang menghalanginya untuk masuk surga." Meskipun ada hadis tersebut ulma tidak berpendapat bahwa membaca ayat kursy setelah shalat itu sunah. Karena itu, membaca ayat kursy setelah shalat wajib itu hal nya bersifat tahsini. ${ }^{12}$ Peneliti mengungkapkan segala aspek yang berkaitan dengan komunikasi ritual dan menganalisis tentang makna yang terkandung didalamnya pembaca dapat memahami makna filosof yang lebih mendalam dalam sebuah ritual kebudayaan tradisional yang berbalut nuansa keagamaan. Berikut makna prosesi acara ritual Suroan

\footnotetext{
${ }^{11}$ Riswandi, "Ilmu Komunikasi”, (Jakarta: Graha Ilmu. 2009), hlm. 19-21.

12 Jaih Mubarok, "Metodologi Studi Islam", (Bandung: PT. Remaja Rosdakarya, 2006), hlm. 129.
} 


\section{a. Makna Prosesi Acara Ritual Suroan}

Ritual Suroan dilaksanakan ba'da sholat Isya (sekitar 19.30 WIB). Masyarakat RT 14 mulai berbondong-bondong menuju ke masjid dengan membawa nasi Takir Pelontang berjumlah sesuai dengan jumlah keluarga dan dilebihkan satu sebagai bentuk rasa syukur atas rumah hunian yang telah diberikan Allah SWT. Sesampainya di masjid nasi Takir yang dibawa, diletakan di tengahtengah ruangan, dan kemudian seluruh penutup nasi Takir Pelontang tersebut dibuka. Mulailah tokoh agama membuka acara ritual suroan dengan mengucapkan salam dan sholawat, kemudian menjelaskan niat diadakan cara ritual Suroan sebagai berikut:

i. Sebagai ungkapan rasa syukur atas nikmat yang telah diberikan Allah hingga saat ini.

ii. Memperbanyak sedekah diawal tahun agar diberikan kemudahan dalam mencari rezeki di tahun yang akan datang.

iii. Berdoa memohon ampunan kepada Allah dan meminta dijauhkan dari mara bahaya dan selalu dalam lindungan-Nya.

Setelah penjelasan niat tentang diadakan ritual Suroan, masuklah pada acara inti yaitu pembacaan surat Al-Qur'an berupa Surat Al- Fatihah, Surat Al-Ikhlas, Surat Al-Falaq dan Surat An-Nas, kemudian dilanjutkan wirid dan diakhiri dengan doa. Acara terakhir adalah penutup, acara ini ditutup dengan mengucapkan alhamdulillah dan di lanjutkan dengan membagikan nasi Takir Pelontang warga terutama anak yatim kemudian di makan bersama-sama dalam masjid tersebut. Lilik Setiawati Sebagai Masyarakat RT 14 Kelurahan Padang Serai kota Bengkulu menuturkan tentang peosesi acara ritual Suroan sebagai berikut:

"Rangkaian acara suroan neng masjid iku, pertama diawali moco surat-surat pendek, terus dilanjutne wirid bareng-bareng dipimpin bapak imam, seng terakhir iku moco doa tolak balak, doa minta keberkahan, kelancara karo nyuwuon keselametan karo seng moho kuoso supoyo neng tahun seng baru iso lebih bersyukur atas nikmat seng wes dikei. Rangkaian acara suroan di masjid itu, pertama diawali membaca surat-surat pendek, kemudian dilanjutkan membaca wirid bersama-sama yang dipimpin bapak imam, dan yang terakhir itu membaca doa tolak balak, doa meminta keberkahan, kelancaran, dan meminta keselamatan terhadap sang maha kuasa agar di tahun yang baru bisa lebih bersyukur atas nikmat yang telah diberikan."13

Dari hasil observasi dan wawancara terhadap masyarakat setempat bahwa ritual Suroan ini memberikan sebuah gambaran jika dilihat dari prosesi awal perayaan suroan hingga akhir menandakan adanya unsur-unsur kebudayaan dan perbaduan dengan Islam. Hal ini dibuktikan dengan adanya bacaan-bacaan surat-surat al-Quran dan dilanjutkan dengan bacaan zikir

${ }^{13}$ Wawancara dengan Lilik Setiawati, Warga RT 14 Kelurahan Padang Serai Kota Bengkulu, 10 Juni 2018. 
bersama kemudian diakhiri dengan doa tolak balak. Dari sinnilah perayaan Suroan ini memiliki pemaknaan yang sangat signifikan perpaduan anatara kebudayaan dan ajaran agama Islam. Secara kebudayaan perayaan suroan memiliki makna filosof tinggi dari masyarakat Jawa Kuno yang kemudian faham filosof ini masih dilestarikan hingga sekarang.

Terlepas dari makna kebudayaan yang turun temurun jika dilihat dari ajaran agama Islam makna suron juga memiliki makna yang sangat islami. Suroan itu sendiri terjadi tepat bulan muharam tepatnya pada tanggal 1 muharam, yang secara kalender Islam merupakan tahun baru Hijriah. Selain itu mkana suroan juga memiliki makna mendalam dalam hal sosial, hal ini dibuktikan dengan adanya saling berbagi dari makanan yang dibawa untuk dimakan bersama dengan masyarakat setempat, tidak memandang ras, suku, dan kedudukan anatara miskin dan kaya. Semua berkumpul satusama lain untuk bermunajat bersama, merendah dan bersyukur kepada sang pencipta atas segala yang didapat hingga saat ini. Dan memohon perlindungan untuh dilancarkan segala urusan dan diajuhakn dari mara bahaya.

\section{b. Komunikasi dalam Ritual Suroan}

Sebuah kebudayaan tentu memiliki proses yang panjang di dalamnya dan tentunya tidak akan pernah lepas dari proses komunikasi, guna mecapai tujuan yang diinginkan. Layaknya sebuah komunikasi dimana proses penyampaian pesan dari komunikator kepada komunikan, didalamnnya terdapat beberapa tahapan untuk menyamaikan pesan itu hingga sampai ketujuan. Ritual Suroan menjadi rujukan bagaimana jalannya komunikasi dalam sebuah ritual kebudayaan. Berikut ini beberapa tahapan penyampaian pesandari komunikator kepada komunikan dalam sebuah ritual Suroan:

i. Peran Tokoh masyarakat dan Pemuka Agama dalam Ritual Suroan. Komunikator merupakan seseorang yang menjadi sumber informasi dalam menyampaikan pesan. 14 dalam prosesi ritual Suroan yang menjadi komunikator ada dua orang diantaranya, tokoh masyarakat sebagai pembawa acara dan tokoh agama yang memimpin jalannya ritual suroan. Tokoh agama memimpin ritual Suroan mulai dari menjelaskan tujuan diadakan ritual Suroan hingga memimpin pembacaan ayat suci Al-Quran hingga doa selamat di akhir ritual Suroan. Pada tahap ini, merupakan tahap penyampaian pesan diawal tentang apa maksud dan tujuan diadakannya ritual suroan tersebut. Penjelasan ini dilakukan agar tidak adanya salah faham, dan persepsi tentang makna dan tujuan diadakannya ritual tersebut. Tokoh agama disini berperan sangat penting untuk memandu jalannya acara serta mengarahkan apa maksud dan tujuan acara ini dilakukan.

\footnotetext{
${ }^{14}$ Riswandi, Ilmu Komunikasi, hlm. 3.
} 
ii. Makna Pesan Komunikasi Ritual Suroan. Makana pesan yang terkandung dalam ritual suroan ini adalah bertujuan untuk memohon ampunan, meminta keberkahan, dan memohon perlindungan agar dijauhkan dari mara bahaya dan bencana. Dalam perayaan Suroan ini masyarakat RT 14 Kelurahan Padang Serai Kota Bengkulu membawa nasi Takir yang bermakna dan bertujuan untuk bersedekah kepada sesama yang nantinya Takir tersebut akan di makan bersama-sama sebagai bentuk persatuan dan rasa syukur atas nikmat yang telah diberikan Allah SWT. Supiyanto selaku ketua RT 14 Kelurahan Padang Serai Kota Bengkulu menuturkan :

"Saya sangat mengapresiasi masyarakat Jawa di Rt 14 ini, meski mereka sudah berpuluhpuluh tahun tinggal di perantauwan mereka masih tetap melestarikan tradisi rirual budaya lokal seperti perayaan Suroan ini. Mereka juga memaknai ritual Suroan ini sebagi bntuk ungkapan rasa syukur atas nikmat yang telah di dapat dan meminta perlindungan terhadap Allah, agar di lancarkan urusan nya di tahun yang akan datang dan di mantapkan ibadahnya."15

iii. Peran Masyarakat dalam Perayaan Ritual Suroan. Komunikan dalam ritual Suroan adalah seluruh masyarakat Rt 14 yang hadir dalam perayaan Ritual tersebut. Komunikan disini bertugas sebagai pendengar dan pelaksana ritual Suroan. Mereka bersama-sama membacakan ayat-ayat suci Al-Qur'an yang dipimpin oleh tokoh agama, membaca wirid bersama-sama dan doa. Semua itu ditujukan hanya kepada Allah SWT sang pemberi rahmat, keberkahan dan ampunan, agar mereka diberikan kemudahan dan selalu berada di jalan allah dalam menghadapi tahun baru yang akan datang. Masyarakat sebagai Komunikan dalam ritual ini memiliki peran yang sangat penting, selain esensi dasar komunikan sebagai penerima pesan, dalam ritual ini komunikan memiliki peran untuk melestarikan budaya dan meperkuat keimanan dan ketakwaan kepada sang khalik untuk terus beryukur atas nikmat serta pertolongan yang senantiasa diberikan Oleh-Nya. Sehingga peran masyarakat sebagai komunikan mampu meningkatkan kualitas aqidah dan kesetaraan sosial, dari perpaduan antara kebudayaan dan agama dalam ritual suroan tersebut.

\section{Makna Komponen Ritual Suroan}

Sesuai dengan sejarah ritual Suroan yang ada, maka komponen dalam ritual ini adalah Takir Pelontang, Takir Pelontang merupakan simbol dalam mengenang perjuangan Nabi Nuh dan bentuk sebagai rasa syukur atas keberkahan dan nikmat yang telah diberikan Allah saat ini sehingga masyarakat yang melaksanakan ritual Suroan ini dengan membuat makanan makanan berupa nasi, lauk pauk (ayam dan kacang-kacangan), kemudian di letakan dalam wadah terbuat

${ }_{15}$ Wawancara dengan Ketua RT 14 Kelurahan Padang Serai Kota Bengkulu, pada 14 Juli 2018. 
dari daun pisang dan di hiasi janur kuning sehingga keseluruhn itu disebut Takir Pelontang. Berikut komponen-komponen perayaan ritual Suroan beserta makna yang terkandung.

\section{a. Takir Pelontang}

Dalam aspek logis, takir ini terbuat dari daun pisang dan diperkuat dengan lidi. Kemudian dipererat dengan Janur kunung yang melingkari takir tersebut. Takir Pelontang memiliki sudut empat, sudut emapat ini bermakan kiblat dari sebagian Jawa dan umat islam seperti halnya Abu bakar, Umar, Usman dan Ali, dengan demikian ada kaitannya dengan Islam. Dari hasil observasi dapat diketahui bahwa, sebuah komponen yang terdapat dalam kegiatan Ritual Suroan memiliki nilai filosofis yang mencerminkan 4 pilar agama Islam. Dari empat sudut melambangkan sebuah ukhuwah Islamiyah yang kuat dengan 4 khalifah yaitu Abu Bakar Asy-Siddiq, Umar bin Khattab, Usman bin Affan, dan Ali bin Abi Thalib.

Secara aspek psikologis, pemaknaan Ritual Suroan dalam komponen Takir Pelontang ini disepakati masyarakat setempat, dan mempercayai bahwa adanya keterikatan satu sama lain dalam masyarakat tersebut untuk menjaga kerukunan, kedamaian dan keberkahan dalam kehidupan. Hal ini ditandai dengan antusiasme masyarakat setempat yang semangat membuat nasi beserta lauk pauknya untuk berbagai kepada sesama pada saat ritual berlangsung.

\section{Gambar 1. Takir Pelontang}

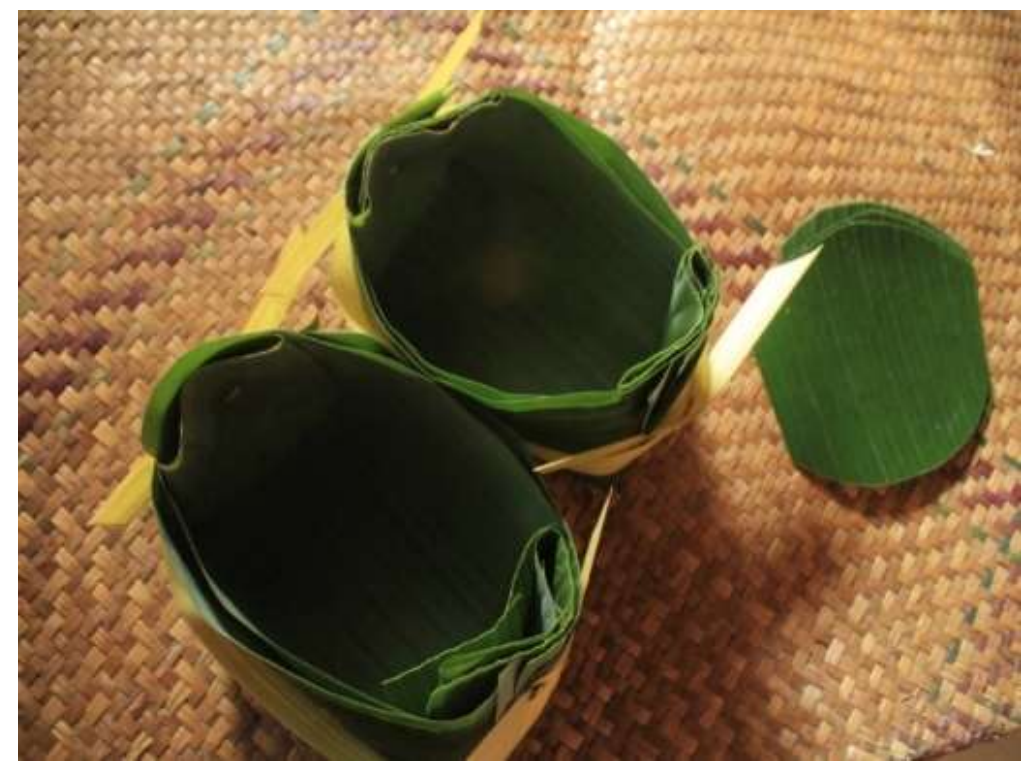

Sumber: Dokumentasi Ritual

\section{b. Sodo}

Dalam sspek logis, kata sodo berasal dari Bahasa Jawa, Sodo merupakan artian dari lidi jika dalam bahasa Indonesia. Dalam pembuatan Takir plontang Sodo menjadi bagian penting yang mempunyai makna memperkuat. Sedangkan jika di artikan sodo dalam kajian Islam Jawa kuno 
diibaratkan sebagai syahadat. Sodo atau lidi tersebut telah memperkuat takir di sisi kiri dan kanan dan diibaratkan sebagai syahadat bagi umat Islam. Maka umat Islam tersebut tentu jika beragama Islam lebih mntap dan lebih sempurna.

Secara aspek psikologis, masyarakat RT 14 Kelurahan Padang Serai kota Bengkulu, memaknai sodo bukan sebagai hal mistik, sesuai dengan filosof yang dikemukakan tokoh adat setempat bahwa dalam pemikiran jawa Kono menganggap bahwa sodo yang digunakan sebagai memperkuat takir (tempat makan) melambangkan ikatan dua kalimat syahadat yang memberikan kedamaian dan keberkahan dalam Islam. Namun, makna sodo ini kurang diterapkan dalam kehidupan dalam masyrakat disisi setempat terutama yang mengikuti ritual tersebut tidak memperkuat aqidah sebagaimana syahadat yang menjadi rukun iman pertama dalam Islam. Fenomena dilapangan masih banyak masyarakat yang tidak melaksanakan sholat, bahkan kerap meninggalkan sholat jum'at. Jadi secara psikologis makna sodo yang dimaknai syahadat belum di aplikasikan dengan baik bagi masyarakat tersebut.

Gambar 2. Sodo atau lidi

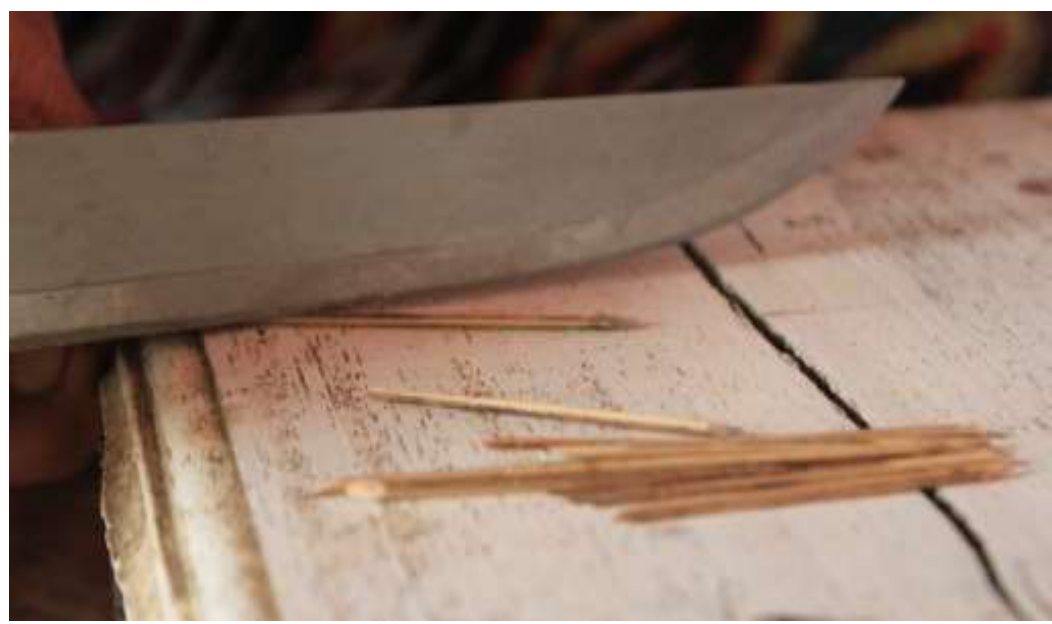

Sumber: Dokumentasi Ritual Suroan

\section{c. Janur}

Dalam aspek logis, janur memiliki makna yaitu secara bahasa janur bersal dari bahasa Arab asal kata $J a-J a^{\prime} a$ artinya datang, Nur itu cahaya dan kemudian janur yang digunakan berwarna kuning. Kuning asal kata qonaa'ah artinya menerima. Janur kuning dipasang takir mengelilingi takir tersebut sehingga berbentuk bulat. Makna dari Janur kuning yang mengelilingi takir adalah merupakan ajaran agama Islam dimana janur tersebut membentuk bulat yang berarti umat Islam hatinya harus bulat untuk berukhuwah satu sama lain sehingga dapat dimaknai supaya semua umat manusia baik muslim atau non muslim untuk berukhuwah, bertekad satu bangsa satu negara dan satu kepercayaan yaitu Ketuhanan yang Maha Esa. Maka dengan adanya janur 
kuning tersebut dapat dikatakan datanglah cahaya dari Allah atau hidayah bagi umat Islam yang telah diterimannya.

Secara aspek psikologis, pemaknaan mengenai janur kuning yang menjadi bagian dari takir plontang dengan filosof bahwa janur kuning menandakan adanya cahaya, sebuah penerangan bagi umat islam. Masayarkat setempat merasakan adanya sebuah ukhuwah islamiah yang kuat, saling menjaga, melndungi dan mengayomi satusama lain. Hal ini dibuktikan dengan adanya kegiatan ritual suroan, masyarakat setempat yang sangat antusias, dengan membawa nasi untuk di makan bersama-sama.

Janur kuning telah membawa pemahaman bagi masayrakat setempat untuk saling menjaga bukanhanya pada sesama muslim yang wajib dilakukan, namun juga ikut mengayomi kepada agama lain, bahwa Islam mengajarkan untuk saling berbagi, menyayangi dan menghormati satu sama lain. Hal inilah yang memperkuat masyarakat setempat untuk saling bertekad menjaga satusama lain.

Gambar 3. Janur kuning

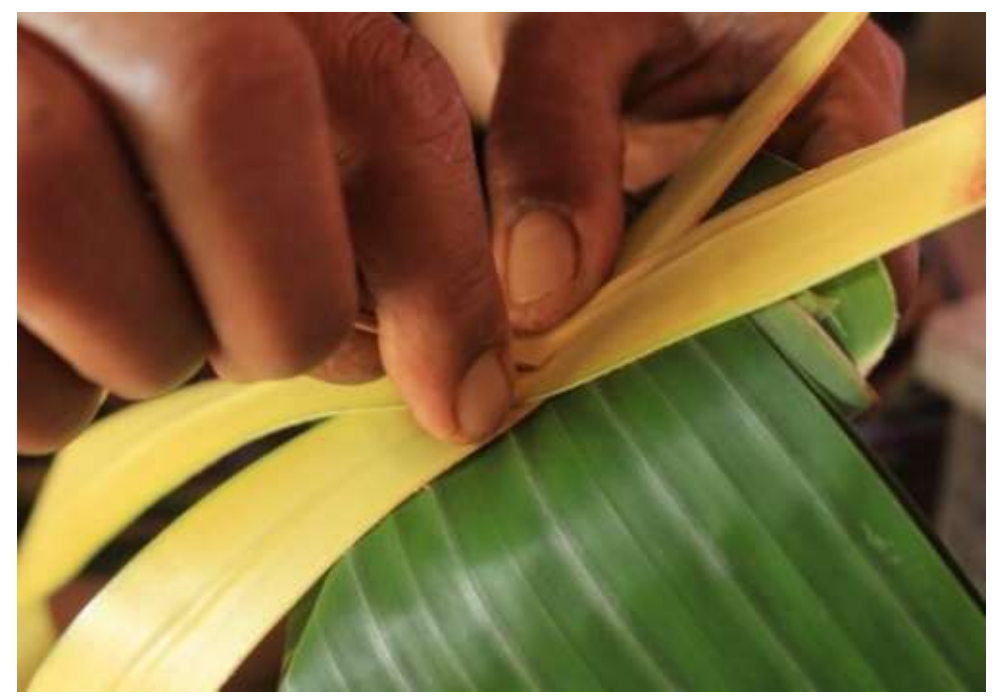

Sumber: Dokumentasi Ritual Suroan

\section{KESIMPULAN}

Makna simbol yang terkandung dalam komponen-komponen terdapat pada ritual suroan diantaranya: 1). Takir Plontang, dimaknai sebagai bentuk solidaritas, keterkaitan satu sama lain antar umat Islam untuk menjaga kerukunan, kedamaian dan keberkahan dalam kehidupan. 2). Sodo, melambangkan ikatan dua kalimat syahadat yang memberikan kedamaian dan keberkahan dalam Islam. 3). Janur Kuing, filosofis bahwa janur kuning menandakan adanya cahaya, sebuah penerangan bagi umat islam. Masayarakat setempat merasakan adanya sebuah ukhuwah islamiah yang kuat, saling menjaga, melndungi dan mengayomi satu sama lain. 
Tujuan mendasar Ritual Suroan ini juga jika dikaitkan dalam ranah sosial sangat berdampak positif, yaitu untuk menyadarkan masyarakat agar hidup rukun, damai, dan saling mengayomi. Ketika dilihat dalam segi kegamanaan juga Ritual Suroan mengajarkan kepada umat Islam untuk terus bersyukur atas nikmat yang telah diberikan Allah SWT, memohon ampunan serta meningkatkan iman dan takwa semata hanya kepada sang khalik Allah SWT. Studi ini secara meyakinkan membantah asumsi-asumsi yang berkembang di masyarakat Indonesia bahwa ritual tradisional cenderung negatif, mempersepsikan budaya lokal beraliran mistis, bahkan memuja Tuhan dengan tidak wajar. Ritual Suroan melalui penjelasan simbol milik Sausanne Langer telah membuktikan bahwa aspek logis dan psikologis memiliki makna dan landasan filosofis Ke-Islaman yang kuat.

\section{DAFTAR RUJUKAN}

Japarudin, "Tradisi Bulan Muharam Indonesia”, Tasaqofah dan Tarikh: Jurnal Kebudayaan dan Sejarah Islam, Vol. 2, No. 2, 2017.

Liliweri, Alo. “Dasar-Dasar Komunikasi Antarbudaya”, Yogyakarta: Pustaka Pelajar, 2009.

Manafe, Yermia Djefri, “Komunikasi Ritual pada Budaya Bertani Atoni Pah Meto di Timor-Nusa Tenggara Timur", Jurnal Komunikasi,Vol. 1, No. 3, 2011.

Morissa, “Teori Komunikasi Individu Hingga Massa”, Jakarta : Kencana, 2011.

Mubarok, Jaih. “Metodologi Studi Islam”, Bandung: PT. Remaja Rosdakarya, 2006.

Novitasari, "Tradisi Unik Perayaan Muharam di Indonesia", https://kumparan.com/ariulandari/17-tradisi-unik-perayaan-muharam-tahun-baru-kalender-bulan-di-indonesia 2017. Diakses pada 25 Oktober 2019.

Rahadi, Setia. "Perayaan Satu Suro Tradisi malam Sakral Masyarakat Jawa", https://www.indonesiakaya.com/jelajah-indonesia/detail/perayaan-satu-suro-tradisimalam-sakral-masyarakat-jawa 2015. Diakses pada 25 Oktober 2019.

Riswandi, "Ilmu Komunikasi”, Jakarta: Graha Ilmu. 2009.

Siburian, Ayu Lusoi M., dan Waston Malau, “Tradisi Ritual Suroan Pada Masyarakat Jawa Di Desa Sambirejo Timur Precut Sei Tuan", Gondang: Jurnal Seni dan Budaya, Vol. 2, No. 2, 2018. Sugiono, "Memahami Penelitian Kualitatif", Bandung: Alfabeta, 2014.

Tantotntsame, "Mengenal Tradisi Malam Satu Suro di Tanah Jawa Ragam-Budaya-Indonesia”, https:/ / www.kaskus.co.id/thread/50a207450975b4d00500013b/mengenal-tradisimalam-satu-suro-ditanah-jawa-ragam-budaya-indonesia/ , akses pada 10 Oktober 2019. 